\title{
Prevalence of breast-related symptoms, health care seeking behaviour and diagnostic needs among women in Burkina Faso
}

\author{
Leonie Ströbele ${ }^{1}$, Eva Johanna Kantelhardt ${ }^{1,2}$, Timongo Francoise Danielle Traoré Millogo ${ }^{3}$, Maurice Sarigda ${ }^{3}$,
} Jürgen Wacker ${ }^{4}$ and Kirstin Grosse Frie ${ }^{1 *}$ (D)

\begin{abstract}
Background: The prevalence of breast cancer has been increasing in sub-Saharan Africa over the last few years. Patients often present with late stage disease, resulting in a high mortality rate. This study aims to estimate the prevalence of breast -related symptoms in the female population of Burkina Faso. The findings can be used to advise on adequate diagnostic health services for breast symptoms to ensure early detection and down-staging of breast cancer.

Methods: A cross-sectional, population based study of 996 women was conducted to investigate the proportion of women with breast-related symptoms. A semi-structured questionnaire was used to collect sociodemographic data, information about breast cancer knowledge and details about breast-related symptoms, health care seeking and medical care. Breast-related symptoms were categorised as currently present/not currently present to estimate the current prevalence of women requiring a diagnostic service.

Results: Among the 996 women, 120 reported having had a breast-related symptom in their life. Only 36 women sought medical advice and eight women had diagnostic confirmation by histological or imaging techniques. Current breastrelated symptoms were reported by 33 women (3.3\% of the sample). An extrapolation to Burkina Faso's female population suggests that 184,562 women are in current need of diagnostic services due to any breast-related symptoms.

Conclusions: Imaging techniques at the community and referral level are needed in order to triage women with breastrelated symptoms. Specialised services need to be strengthened to ensure appropriate diagnosis and treatment of breast diseases. Education campaigns among the general population and among health care professionals are required to increase awareness of breast cancer and improve prompt health care seeking and referral.
\end{abstract}

Keywords: Breast Cancer, Cancer early detection, Sub-Saharan Africa, Health care seeking behavior, Health care system

\section{Background}

The rise of non-communicable diseases (NCD) has become an important issue for health-care systems. Over the last few decades, national and international public health agencies have focused on controlling infectious and tropical diseases in developing countries. In developing countries, $80 \%$ of deaths occur due to NCD [1],

\footnotetext{
* Correspondence: grossefrie@web.de

${ }^{1}$ Martin-Luther-University Halle-Wittenberg, Institute for Medical

Epidemiology, Biostatistics and Informatics, Magdeburger Straße 8, 06112

Halle, Germany

Full list of author information is available at the end of the article
}

and deaths from NCDs are predicted to increase in African countries by $27 \%$ over the next 10 years [2]. In 2012, the prevalence of cancer was estimated to be higher in developing countries, with more than eight million cases, compared to more developed regions, with more than six million cases. At the same time, breast cancer was diagnosed in about $25 \%$ of all newly diagnosed cancers worldwide, and became the most frequent cause of cancer death for women in less developed regions, with 324,000 cases per year [3]. The reasons for the increasing incidence of breast cancer in developing countries include previous underdiagnoses as well as changes in lifestyle and 
reproductive behaviours and a higher life expectancy [4]. In 1994, one of the goals of the International Conference on Population and Development was to make prevention and treatment of breast cancer part of the reproductive system, and globally accessible by 2015 [5]. The reality is, that case fatality and survival rates [6, 7] of breast cancer still differ remarkably between developing and developed countries. While women diagnosed with breast cancer in the United States have an 85-90\% chance of five-year age-standardized survival [8], women with breast cancer in Gambia, one of the lowest-income countries in Africa, have only a $12 \%$ chance of 5-year age-standardized survival [9].

It is expected that, by 2025 , the maternal mortality rate in developing countries will continue to decrease and breast cancer mortality will increase, so that both factors will be nearly identical among women of reproductive age [10]. This implies an immense challenge for resource-poor countries in which facilities for diagnostics and therapy are very limited, and the cost of suitable breast cancer care generally outweighs the monthly income [11]. Several studies from sub-Saharan Africa have shown that the majority of breast cancer patients are diagnosed at a late stage, making treatment more difficult and less effective [12, 13]. Factors that explain late presentation to health care providers have been described at the individual level (low breast cancer awareness and knowledge, misconceptions and mythical beliefs, mistrust in the health care system, financial and access barriers) and at the health system level (low quality and availability of health care services, absence of specialised public services and necessary drugs, high diagnosis and treatment costs, low knowledge and no referral among health professionals, lack of health insurance) [14-18]. Considering these difficulties, the problem may be tackled at its roots by implementing intensified research regarding risk factors for breast cancer, focusing on the creation of awareness and on early detection programs to prevent deaths from breast cancer. Breast cancer screening programs are implemented nationwide in high-income countries, but are lacking and likely to be ineffective and unaffordable in Low- and Middle Income Countries (LMICs) with a young population and insufficient local treatment options [19].

Early detection of breast cancer requires verification of all breast symptoms. Raising knowledge and awareness about breast cancer in a population requires a properly working health system where adequate breast health care is ensured for every woman who notices breast-related symptoms. To guide the development and strengthening of such a health care system, it is important to estimate the prevalence of breast symptoms which need diagnostic service, and likely follow-up and treatment. Burkina Faso, according to the Human Development Index, is one of the five least developed countries in the world. Health care is very limited and no general health insurance coverage is available. It is estimated that 1144 women develop breast cancer every year in Burkina Faso, and every second woman will die from it [3]. In the capital's university medical centre, the main tertiary referral centre of Burkina, there is only one breast cancer specialist and very limited diagnostic and therapeutic options. Radiotherapy is nonexistent throughout the whole country, despite the fact that it is estimated there could be a benefit, in terms of survival, for $50-60 \%$ of cancer cases [20].

This study aimed to estimate the prevalence of breastrelated symptoms, breast cancer knowledge, health care seeking behaviour and diagnostic needs among women in Burkina Faso.

\section{Methods \\ Setting}

A cross-sectional population-based survey was conducted to assess the diagnostic needs and barriers to health care seeking with a semi-structured questionnaire among females in Burkina Faso. Burkina Faso's population is divided into counting units, the "Zones de dénombrement". There are 1217 urban and 11,165 rural zones in which each zone has about 1000 habitants [21]. After stratification by urban and rural population five districts (Secteur 15, Secteur 20, Secteur 23 of the capital for urban areas and the villages Boena and Siralo for rural areas) were randomly selected, proportional to population size.

The northern areas of Burkina Faso were excluded due to political disturbances.

\section{Data collection}

The data collection took place from mid-December 2015 until the end of February 2016. According to the results of a previous study [6], which investigated the prevalence of breast masses in Ruanda and Sierra Leone as identified by the Surgeons Overseas Assessment of Surgical Need (SOSAS), a sample size of 945 women was calculated based on the assumption of $4 \%$ prevalence and the required precision of $+/-1.25 \%$ for the $95 \%$ confidence interval. Women were eligible for inclusion if they were 18 years of age or older and if they gave voluntary informed consent for participation. A total of 996 women were interviewed. Local medical students were trained by one of the investigators in terms of breast health, sampling strategies and interview techniques. Data collection was conducted via face to face interviews. In each selected district, a pencil was thrown in the air at a public place, and the direction in which the pencil tip pointed indicated the starting point for the interviews. Consecutively, in each household, one female member of each family, aged 18 years or older, was interviewed until the number of women to be surveyed in the selected district was reached. All women except ten agreed to participate in the study. 
The questionnaire was composed in French, but individually translated to the local language. The questionnaire included parts of the SOSAS survey [22], in order to obtain information about the lifetime incidence and current prevalence of breast-related symptoms, as well as diagnostic need and barriers to health care seeking. The questionnaire was piloted among 15 women. Understanding of the questions was good and only minor changes were made to improve fluency of the interviews. The questionnaire was subdivided into five different chapters: sociodemographic and socio-economic situation (A), risk factors for breast cancer (B), past or present breast pathologies (C), knowledge about breast cancer and breastself-examination (BSE) (D) and barriers to seeking health care $(E)$. After the interview, each woman received training on breast symptom awareness and self-examination. In the case of current suspicious self-reported symptoms, referral to a health care centre was ensured.

During the interview, answers were noted on the questionnaire and afterwards were checked for consistency and entered in a database (MS ACCESS 2016) by one of the investigators.

\section{Statistical analysis}

The main question was about presence or ever presence of breast-related symptoms. Generally we assumed all breast-symptoms would need diagnostic assessment to rule out breast cancer. For descriptive purposes, leading breast-related symptoms were classified into groups (e.g. painful tension, breast mass) and whether they were associated with breastfeeding or not. The current status of women who reported any breast-related symptoms in their lifetime was categorised as follows: women who had a diagnostic service, women who had a surgical intervention without any diagnosis, women who had no current symptoms and women who currently had unverified symptoms. The percentage of currently unverified symptoms was used to extrapolate the results to Burkina Faso's female population. Regarding the age structure, our study sample is representative for the general population of Burkina Faso, as age groups within the study sample are comparable to the ones listed in the World Fact Book of 2016 [23]. Descriptive data analysis was performed using SPSS 19.

\section{Results}

Data from 996 interviewed Burkinabe women, aged 18 years or older, was analysed. Sociodemographic data is described in Table 1.

\section{Breast cancer knowledge}

Women were asked to rate their subjective knowledge about breast cancer on a scale between 1 (good) and 10 (bad). The average score was 8,29 . This low self-rated
Table 1 Sample characteristics, all women $(n=996)$

\begin{tabular}{|c|c|}
\hline & $n \%$ \\
\hline Age in years [m], (sd) & $33.4(12.5)$ \\
\hline \multicolumn{2}{|l|}{ Age group } \\
\hline $18-30$ years & $529(53.1)$ \\
\hline $31-45$ years & $302(30.3)$ \\
\hline $46-86$ years & $158(15.9)$ \\
\hline Missing & $7(0.7)$ \\
\hline \multicolumn{2}{|c|}{ Highest level of education } \\
\hline None & $557(55.9)$ \\
\hline Elementary school & $192(19.3)$ \\
\hline Secondary school & $134(13.5)$ \\
\hline Tertiary school & $57(5.7)$ \\
\hline University & $55(5.5)$ \\
\hline Missing & $1(0.1)$ \\
\hline \multicolumn{2}{|l|}{ Literate } \\
\hline Yes & $400(40.2)$ \\
\hline No & $596(59.8)$ \\
\hline \multicolumn{2}{|l|}{ Occupation } \\
\hline Housewife & $167(16.8)$ \\
\hline Farmer & $396(39.8)$ \\
\hline Business & $323(32.4)$ \\
\hline Public service & $25(2.5)$ \\
\hline Student & $47(4.7)$ \\
\hline Other & $38(3.8)$ \\
\hline \multicolumn{2}{|l|}{ Married } \\
\hline Yes & $795(79.8)$ \\
\hline No & $201(20.2)$ \\
\hline \multicolumn{2}{|l|}{ Religion } \\
\hline None & $2(0.2)$ \\
\hline Islam & $721(72.4)$ \\
\hline Christian & $271(27.2)$ \\
\hline Missing & $2(0.2)$ \\
\hline \multicolumn{2}{|l|}{ Residence } \\
\hline Urban & $583(58.5)$ \\
\hline Rural & $413(41.5)$ \\
\hline \multicolumn{2}{|l|}{ Births } \\
\hline 0 & $157(15.7)$ \\
\hline $1-3$ & $459(46.0)$ \\
\hline $3+$ & $380(38.2)$ \\
\hline \multicolumn{2}{|l|}{ Nursing period } \\
\hline No children & $157(15.7)$ \\
\hline$<12$ months & $6(0.6)$ \\
\hline 12-24 months & $402(40.4)$ \\
\hline 24-36 months & $404(40.6)$ \\
\hline$>36$ months & $12(1.2)$ \\
\hline Missing & $15(1.5)$ \\
\hline
\end{tabular}


level of knowledge was also evident in other breast cancer knowledge-related questions. A single open question concerning risk factors for breast cancer was answered by $87 \%$ of all women as 'no idea'. A minority stated nutrition $(n=57)$, reproductive reasons $(n=19)$, heredity or age $(n=7)$ as "correct" risk factors. Other factors stated were mechanical reasons like carrying money or cell phones under the bra $(n=60)$, use of aesthetic products $(n=15)$, and infection or externals $(n=14)$. A minority of all women (11.3\%) stated that they knew about BSE. Questions concerning the time-point and frequency of practicing BSE were answered correctly by only 14 and 26 women, respectively. One quarter of all women had never heard about breast cancer. Among those who had heard about it, almost 25\% were not sure if breast cancer could be deadly if not treated. The 749 women who had heard about breast cancer were asked where they had heard about it. Results are shown in Fig. 1.

\section{Breast related symptoms}

Having had breast-related symptoms at least once in their lifetime was reported by 120 women. The reported primary symptoms are described in Table 2 . In $65 \%$ of all cases, the symptoms were reported as associated in time with breastfeeding. Out of the 120 women with breast-related symptoms, $30 \%$ presented to a health care provider to get medical advice (Table 2). The reasons for not seeking medical advice were primarily absence of disability associated with the symptoms, which led to symptom ignorance, as well as lack of money, no confidence in doctors, no access to health care centres and shame about the disease. A diagnostic confirmation by histopathology or imaging techniques was reported by eight women, and five women reported having had surgical treatment without any diagnostic confirmation (Table 2). Among 74 women who reported having had breast symptoms in the past but had no current symptoms, 28 received medical treatment from a health care facility, 32 used a form of self-medication or went to a traditional healer and in 14 cases, symptoms were self-limiting. Current unverified symptoms were reported by 33 women (3.3\% of the study sample). In 16 cases, the symptoms were associated with breastfeeding. Taking into account that Burkina Faso's female population aged over 15 years is estimated to be 5,592,800 women, it can be estimated that 184,562 women would be in current need of diagnostic services due to any breast-related symptoms.

\section{Discussion}

In our study population, $12 \%$ of all interviewed women reported having had any breast-related symptoms at least once in their lifetime, and 3.3\% had a current unverified breast-related symptom at time of the interview. The extrapolation to the female population of Burkina Faso shows a current need for diagnostic service among 184,562 women in Burkina Faso. Symptoms are rarely related to breast cancer, but a medical check-up with a minimum of ultrasound diagnosis would ideally be recommended to every one of these women. Generally, a sufficient diagnostic service concerning breast symptoms would include availability of physician's CBE (Clinical Breast Examination), ultrasound, biopsies or fine-needle aspiration, and mammography in specialised centre.

In fact, there are little or no facilities for breast health care, and structural barriers exist in Burkina Faso's hierarchically organized national health care system. In the case of breast-related symptoms, women would typically first visit the broadly available very basically equipped reference centres, called CSPS (Centre de Santé et de Promotion Sociale, 1760 centres). No doctors and no surgery facilities are available at these centres; similarly, the next highest reference step, called CMA (Centre

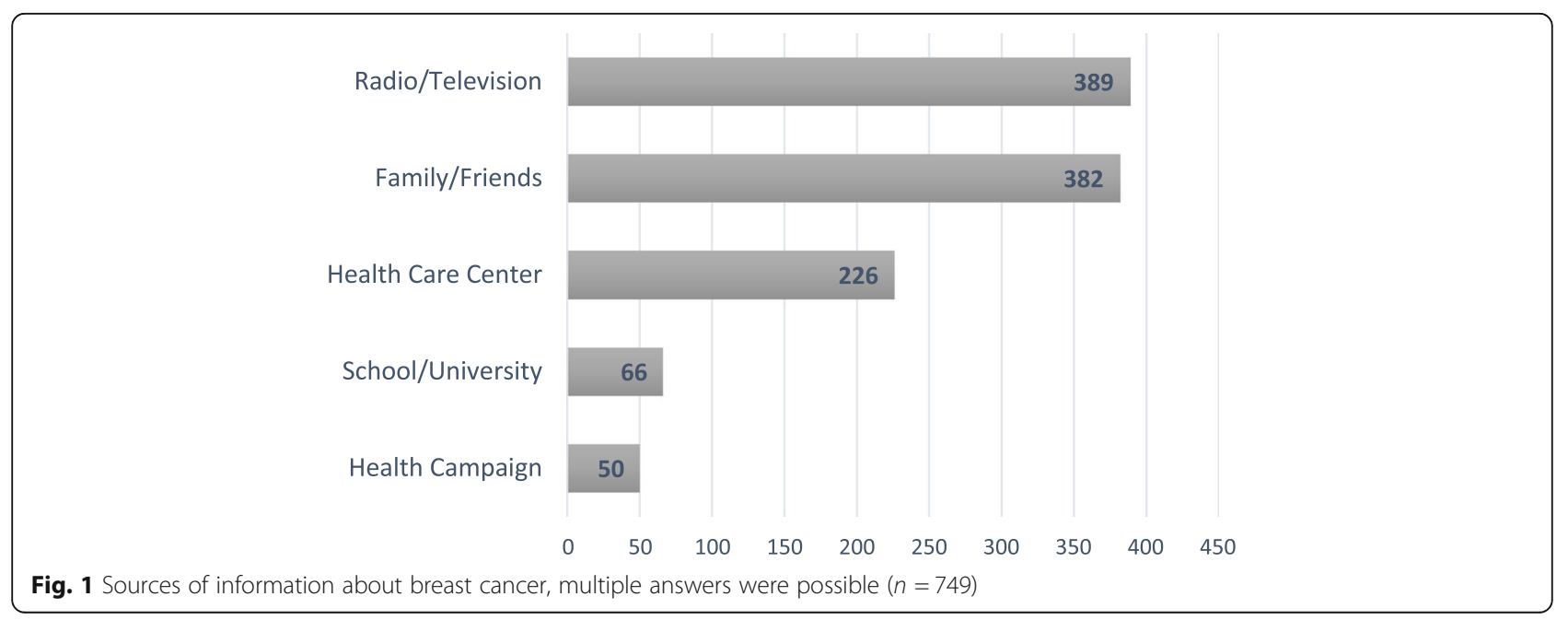


Table 2 Primary symptoms, health seeking and current status, all women with breast-related symptoms $(n=120)$

n \%

\begin{tabular}{ll}
\hline Primary symptoms & $33(27.5)$ \\
Painful tension & $25(20.8)$ \\
Painful tension with appearance of purulence & $17(14.2)$ \\
Pain & $23(19.2)$ \\
Breast mass & $12(10.0)$ \\
Painful tension with redness & $4(3.3)$ \\
Changing of the nipple & $4(3.3)$ \\
Itchiness & $2(1.7)$ \\
Redness & \\
Health seeking after first symptoms & $36(30.0)$ \\
Medical advice & $32(26.7)$ \\
Traditional medicine & $52(43.3)$ \\
Nothing & \\
Current status & $8(6.7)$ \\
Had diagnostic service & $5(4.2)$ \\
Surgery without diagnostic service & $74(61.7)$ \\
No current symptom & $33(27.5)$ \\
Current symptom &
\end{tabular}

Médical avec Antenne Chirurgicale, 47 centres), also does not provide infrastructure for breast care. According to the newest guidelines of the $\mathrm{BC} 2.5$ initiative at the Fred Hutchinson Cancer Research Centre [24], training regarding $\mathrm{CBE}$ among health care providers in the very basic health care reference levels, or among trained nonphysician providers, education about risk factors and symptoms, and creation of awareness of breast cancer among both medical staff and the general population, may improve survival, lower morbidity and reduce the cost of care. A study in Sudan suggested that in breastexamination trained laywomen can provide breast cancer screening [25], and a Tanzanian study reported a down staging of breast cancer in a program to downstage cancer by trained lay personnel [26]. It should be noted that medical specialists are available at the third level reference, called CHR (Centre Hospitalier Regional, 11 centres) and CHU (Centre Hospitalier Universitaire, 5 centres), but these too are not sufficiently equipped with breast ultrasound or diagnostic mammography for breast care.

In our study, only $30 \%$ of 120 women who reported having had any breast-related symptoms in their life sought medical advice. Common reasons for not seeking care were ignorance and lack of money; this is consistent with other studies which have reported these factors to be barriers to health care seeking among breast cancer patients in sub-Saharan Africa [6, 17, 27]. Another reason for not seeking health care might be the low level of knowledge about breast cancer, which was evident in our study and was also reported in several other studies from Sub-Saharan Africa, mainly among breast cancer patients $[6,14,15,17]$. Furthermore, the mentioned risk factors (e.g., carrying money or mobile phones in the bra) for breast cancer reflect notions of stigma and myths which may come along with breast-related symptoms; these might hinder women to seek health care, but might also be related to the use of traditional medicine, as was reported in the neighbouring countries of Ghana [28] and Mali [17].

To improve the situation of breast health care in Burkina Faso, in accordance with the above-mentioned guidelines [24], we suggest that it is imperative to increase awareness and knowledge about breast cancer among the general female population. Awareness and education campaigns have to consider the low literacy rate among women in Burkina Faso, and might be best suited as part of maternal health care services. Teaching of BSE could additionally create awareness and early symptom detection.

However, without adequate diagnostic and treatment facilities, awareness campaigns alone cannot lead to improved breast cancer care and survival. Therefore, ultrasound facilities need to be allocated to every CMA, which means at least 47 instruments for the whole country. Breast ultrasound is helpful to distinguish harmless fluid-filled cysts from suspect solid masses, and can be helpful to provide additional information about the extent of the tumour [29], especially against the background that a high number of breast cancer patients in LMICs present with locally advanced breast cancer. Moreover, mammography is currently the most effective screening tool for breast cancer. This is recommended for women aged 50 years and older, but not for the younger population [19]. In terms of diagnostic mammography, five mammograms in total are needed to ensure adequate equipment in each $\mathrm{CHU}$, and specialists in analysing both ultrasound and mammography imagery need to be provided. The Burkinabe government has to put more effort in to upgrading pathology services, which are still limited to the $\mathrm{CHU}$ and private clinics. Establishing infrastructure for telepathology and assisting pathology laboratories might be a solution.

To strengthen the health system as proposed, support from international stakeholders is needed, as well as public private partnerships. To ensure that the standard treatment options for breast cancer, such surgery, radiation therapy and systemic therapy, are accessible to all patients in LMICs such as Burkina Faso, universal health coverage might be a solution in the long run.

Our study gives a representative picture of breastrelated symptoms in the Burkinabe female population. There are some limitations that should be noted. First, 
the breast symptoms were self-reported and there may have been recall bias, as minor symptoms that appeared a long time ago might have been missed. Therefore, we assume that actual figures regarding lifetime incidence of breast-related symptoms are probably much higher than reported. Secondly, we did not perform an actual on-site assessment of the health facilities; for logistic reasons, we only obtained information about public diagnostic facilities from local health professionals. Health facilities may possibly have better equipment than the overall lack which we report here, especially as private clinics were not considered.

\section{Conclusions}

Only $6,7 \%$ of all women with breast symptoms had received a diagnostic confirmation by histopathology or imaging techniques and 4,2\% reported having had surgical treatment without any diagnostic confirmation. There is a huge need to improve diagnostic service and its utilisation for breast symptoms in Burkina Faso's health care system.

An extrapolation showed a current need for diagnostic services among an estimated 184,562 women with breast-related symptoms in Burkina Faso. Awareness on need for diagnostic assessment of breast symptoms among the general female population has to be increased, and solutions to improve health worker's education and to strengthen the health care system, including upgrading of diagnostic and treatment facilities, are needed.

\section{Abbreviations}

BSE: Breast-Self-Examination; CBE: Clinical Breast Examination; CHR: Centre Hospitalier Regional; CHU: Centre Hospitalier Universitaire; CMA: Centre Médical avec Antenne Chirurgicale; CSPS: Centre de Santé et de Promotion Sociale; LMICs: Low- and Middle-Income Countries; NCD: Non-Communicable Diseases; SOSAS: Surgeons Overseas Assessment of Surgical Need

\section{Acknowledgments}

The authors thank the women who participated in this study. They also thank the dedicated team of study research assistants, notably Samuel Sissao Wendpanga, Noel Gnada, Sinaly Soare, Drissa Sourgou, Pierre Konkobo, Yéli Kam and Mariam Bagayogo.

\section{Funding}

This research was supported by AG FIDE (Women's Health in International Development) of the German Society of Obstetrics and Gynaecology (DGGG). Publication fees were covered by Open Access Publishing by the German Research Foundation (DFG).

\section{Availability of data and materials}

The datasets used and/or analyzed during the current study will be available from the corresponding author on reasonable request.

\section{Authors' contributions}

LS, JW, EK, FMTT and MS conceived of the study and participated in its design. LS, MS and FMTT conducted the research and collected the data. LS, EK and KGF analysed the data and wrote the manuscript, KGF supervised data analysis and manuscript writing. All authors read and approved the final manuscript.

\section{Ethics approval and consent to participate}

Before data collection, permission was granted by the Burkinabe National Health Ministry, and ethical approval was granted from the ethical review committees in Burkina Faso (Comité d'Ethique et de Déontologie) and Germany (Medical School of Heidelberg). Declaration of written consent was obtained from each woman before starting the interview. The respondents did not receive any incentives; however, they were taught about the use of BSE and the detection of breast cancer symptoms after the interview. Finally, the questionnaires and the informed consent form were marked with an individual number to ensure anonymity.

\section{Consent for publication}

Not applicable.

\section{Competing interests}

The authors declare that they have no competing interests.

\section{Publisher's Note}

Springer Nature remains neutral with regard to jurisdictional claims in published maps and institutional affiliations.

\section{Author details}

${ }^{1}$ Martin-Luther-University Halle-Wittenberg, Institute for Medical Epidemiology, Biostatistics and Informatics, Magdeburger Straße 8, 06112 Halle, Germany. ${ }^{2}$ Department of Gynaecology, Martin-Luther-University Halle-Wittenberg, Ernst-Grube-Str. 40, 06097 Halle, Germany. ${ }^{3}$ Unité de Formation en Sciences de la Santé, Université Ouaga 1 Professeur Joseph Ki Zerbo 03 B.P. 7021, Ouagadougou 03, Burkina Faso. ${ }^{4}$ Fürst-Stirum-Klinik Bruchsal, Gutleutstraße 1-14, 76646 Bruchsal, Germany.

Received: 20 December 2017 Accepted: 22 March 2018

Published online: 04 April 2018

\section{References}

1. WHO. WHO preventing chronic diseases: a vital investment. Geneva: World Health Organization; 2005. http://www.who.int/chp/chronic_disease_report/ contents/part1.pdf?ua=1. Accessed 03 Nov 2017

2. WHO Global action plan for the prevention and control of noncommunicable diseases 2013-2020. 2013 http://apps.who.int/iris/ bitstream/10665/94384/1/9789241506236_eng.pdf. Accessed 03 Nov 2017.

3. International Agency on Research on Cancer, WHO. GLOBOCAN 2012: Estimated Cancer Incidence, Mortality and Prevalence Worldwide. 2012 http:// globocan.iarc.fr/Pages/fact_sheets_cancer.aspx. Accessed 03 Nov 2017.

4. Porter P. "Westernizing" women's risks? Breast cancer in lower-income countries. N Engl J Med. 2008;358(3):213-6. https://doi.org/10.1056/NEJMp0708307.

5. United Nations Population Information Network. International Conference On Population And Development: Programme of Action of the Conference (94/5/12). 1994. http://www.un.org/popin/icpd/conference/offeng/eng694. html. Accessed 03 Nov 2017.

6. Ntirenganya F, Petroze RT, Kamara TB, et al. Prevalence of breast masses and barriers to care: results from a population-based survey in Rwanda and Sierra Leone. J Surg Oncol. 2014;110(8):903-6. https://doi.org/10.1002/jso.23726.

7. Kantelhardt EJ, Zerche $P$, Mathewos A, et al. Breast cancer survival in Ethiopia: a cohort study of 1,070 women. Int J Cancer. 2014;135(3):702-9. https://doi.org/10.1002/ijc.28691.

8. National Cancer Institut. Cancer Stat Facts: Female Breast Cancer. 2013 https:// seer.cancer.gov/statfacts/html/breast.html\#survival. Accessed 03 Nov 2017.

9. Sankaranarayanan $\mathrm{R}$, Swaminathan $\mathrm{R}$, Brenner $\mathrm{H}$, et al. Cancer survival in Africa, Asia, and central America: a population-based study. Lancet Oncol. 2010;11(2):165-73. https://doi.org/10.1016/S1470-2045(09)70335-3.

10. Institute for Health Metrics and Evaluation. The challenge ahead: Progress and setback in breast and cervical cancer. 2011 file://C:/Users/Leo/AppData/Local/ Packages/Microsoft.MicrosoftEdge_8wekyb3d8bbwe/TempState/Downloads/ The_Challenge_Ahead_IHME_Policy_Report_0911.pdf. Accessed 03 Nov 2017.

11. Corbex M, Burton $R$, Sancho-Garnier H. Breast cancer early detection methods for low and middle income countries, a review of the evidence. Breast. 2012;21(4):428-34. https://doi.org/10.1016/j.breast.2012.01.002.

12. Jedy-Agba E, McCormack V, Adebamowo C, et al. Stage at diagnosis of breast cancer in sub-Saharan Africa: a systematic review and meta-analysis. Lancet Glob Health. 2016:4(12):e923-35. https://doi.org/10.1016/S2214109X(16)30259-5. 
13. Kantelhardt EJ, Cubasch H, Hanson C. Taking on breast cancer in East Africa: global challenges in breast cancer. Curr Opin Obstet Gynecol. 2015;27(1): 108-14. https://doi.org/10.1097/GCO.0000000000000139.

14. Akuoko CP, Armah E, Sarpong T, et al. Barriers to early presentation and diagnosis of breast cancer among African women living in sub-Saharan Africa. PLoS One. 2017;12(2):e0171024. https://doi.org/10.1371/journal.pone.0171024.

15. Kantelhardt E, Muluken $G$, Sefonias $G$, et al. A review on breast Cancer care in Africa. Breast Care (Basel). 2015;10(6):364-70. https://doi.org/10.1159/000443156.

16. Gadgil A, Sauvaget C, Roy N, et al. Breast Cancer awareness among middle class urban women-a community-based study from Mumbai, India. Asian Pac J Cancer Prev. 2015;16(15):6249-54.

17. Grosse Frie K, Samoura H, Diop S, Kamate B, Traore CB, Malle B, et al. Why Do Women with Breast Cancer Get Diagnosed and Treated Late in SubSaharan Africa? Perspectives from Women and Patients in Bamako, Mali. Breast Care. 2018;13(1):39-43.

18. Sankaranarayanan R, Ramadas K, Grosse Frie K, Qiao YL. Challenges for breast and gynecological cancer control by early detection in less developed countries. In: Shetty MK, ed. Breast and Gynecological Cancers: An Integrated Approach for Screening and Early Diagnosis in Developing Countries. New York: Springer; 2013. pp. 215-27.

19. Panieri E. Breast cancer screening in developing countries. Best Pract Res Clin Obstet Gynaecol. 2012;26(2):283-90. https:/doi.org/10.1016/j.bpobgyn.2011.11.007.

20. Ministère de la Santé (2017) Plan stratégique de lutte contre le cancer 2013-2017. http://www.iccp-portal.org/system/files/plans/Burkina\%20Faso Plan\%20strat\%C3\%A9gique\%20de\%20lutte\%20contre\%20le\%20cancer\%20 2013-2017.pdf. Accessed 03 Nov 2017.

21. Ministère de l'economie et de finances. Recensement general de la population et de l'habitation de 2006. 2008. http://www.insd.bf/documents/ publications/insd/publications/resultats_enquetes/autres\%20enq/Resultats_ definitifs_RGPH_2006.pdf. Accessed 03 Nov 2017.

22. Groen RS. SOSAS Surgeons OverSeas Assessment of Surgical Needs: A manual for SOSAS interviewers, Version 3.0,. 2014. http://www. adamkushnermd.com/files/SOSAS_survey2.pdf. Accessed 03 Nov 2017.

23. Central Intelligence Agency. The World Factbook: Burkina Faso. 2017. https://www.cia.gov/library/publications/the-world-factbook/geos/uv.html. Accessed 03 Nov 2017.

24. Fred Hutchinson Cancer Research Center. Breast Cancer initiative 2.5: making breast health a global priority. Breast Cancer risk factors and risk reduction. 2017. http://www.fredhutch.org/en/labs/phs/projects/breastcancer-initiative_2-5.html

25. Abuidris DO, Elsheikh A, Ali M, et al. Breast-cancer screening with trained volunteers in a rural area of Sudan: a pilot study. Lancet Oncol. 2013;14(4): 363-70. https://doi.org/10.1016/S1470-2045(12)70583-1.

26. Ngoma T, Mandeli J, Holland JF. Downstaging cancer in rural Africa. Int J Cancer. 2015;136(12):2875-9. https://doi.org/10.1002/ijc.29348

27. Kohler RE, Gopal S, Miller AR, et al. A framework for improving early detection of breast cancer in sub-Saharan Africa: a qualitative study of help-seeking behaviors among Malawian women. Patient Educ Couns. 2017;100(1):167-73. https://doi.org/10.1016/j.pec.2016.08.012.

28. Opoku SY. Knowledge, attitudes, beliefs, behaviour and breast cancer screening practices in Ghana, West Africa. 2012. http://www.panafricanmed-journal.com/content/article/11/28/full/

29. Fornage BD, Toubas O, Morel M. Clinical, mammographic, and sonographic determination of preoperative breast cancer size. Cancer. 1987;60(4):765-71.

\section{Submit your next manuscript to BioMed Central and we will help you at every step:}

- We accept pre-submission inquiries

- Our selector tool helps you to find the most relevant journal

- We provide round the clock customer support

- Convenient online submission

- Thorough peer review

- Inclusion in PubMed and all major indexing services

- Maximum visibility for your research

Submit your manuscript at www.biomedcentral.com/submit 